\title{
THE FRAGMENTATION OF GONDWANA: USING DINOSAURS TO TEST BIOGEOGRAPHIC HYPOTHESES
}

FORSTER, Catherine A., Department of Anatomical Sciences, Health Sciences Center, S.U.N.Y. at Stony Brook, Stony Brook, NY 11794, U.S.A.

Madagascar, with the Indian subcontinent attached to its eastern margin, separated from Africa in the Late Jurassic, and reached its current position relative to Africa (approximately 400 kilometers across the Mozambique Channel) by the Early Cretaceous. In the Late Cretaceous, the Indian subcontinent broke free of the eastern margin of Madagascar, leaving Madagascar an isolated island for the last 85 million years. The effect of this break-up on the faunas of these areas is almost completely unknown.

Dinosaurs, as the primary constituent of these faunas, have an enormous potential for testing biogeographic hypothesis regarding the fragmentation of this part of Gondwana. Unfortunately, next to nothing is known of Cretaceous faunas from either southern African or Madagascar. The situation in India is slightly better and ongoing field work by a number of scientists is beginning to rectify this situation. Madagascar, the "keystone" in this story of continental fragmentation, and southern Africa remain in dire need of paleontological attention. To begin filling in this vast gap in our knowledge, I am involved in field projects in both these areas.

I and colleagues have spent two field seasons in the Upper Cretaceous (Campanian) Maevarano Fm., northwestern Madagascar. Prior to our work, only three dinosaur taxa were known from very fragmentary material: Titanosaurus madagascariensis, a titanosaurid, Majungasaurus crenatissimus, a probable abelisaurid, and Majungatholus atopus, a purported pachycephalosaurid. Thus far we have identified two distinct taxa of sauropods, including a nearly complete skeleton of an as-yet undetermined titanosaurid, and found additional material of Majungasaurus, a new taxon of small theropod, and at least three taxa of avian theropods (birds). All these specimens are exquisitely preserved; elements are often found isolated or in association, and occasionally fully articulated. A rich non-dinosaurian fauna also occurs that includes frogs, snakes, crocodilians, lizards, fish, and mammals. Some of these taxa (e.g., frogs and freshwater fish) may also prove crucial in testing biogeographic hypotheses.

In southern Africa, we are conducting field work in the Early Cretaceous Kirkwood Fm., South Africa. We have found evidence of both brachiosaurid and titanosaurid sauropods, and a small unidentified theropod, as well as discovering a new, small iguanodontian that may be closely related to Dryosaurus (known from the Late Jurassic Tendaguru Beds of Tanzania). As work continues in the Kirkwood Fm., we will move north to Zimbabwe this summer to investigate the Cretaceous Gokwe Fm. 